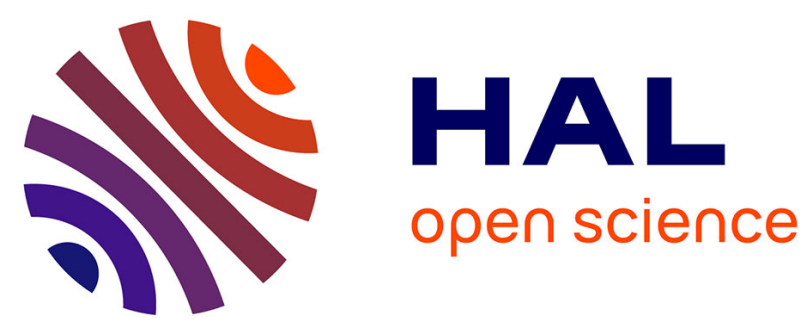

\title{
COLD WELDING AND FRETTING TESTS ON QUASICRYSTALS AND RELATED COMPOUNDS
}

Muriel Sales, Andreas Merstallinger, Pierre Brunet, Marie-Cécile de Weerd, Varsha Khare, Gerhard Traxler, Jean-Marie Dubois

\section{- To cite this version:}

Muriel Sales, Andreas Merstallinger, Pierre Brunet, Marie-Cécile de Weerd, Varsha Khare, et al.. COLD WELDING AND FRETTING TESTS ON QUASICRYSTALS AND RELATED COMPOUNDS. Philosophical Magazine, 2006, 86 (06-08), pp.965-970. 10.1080/14786430500313838 . hal00513608

\section{HAL Id: hal-00513608 \\ https://hal.science/hal-00513608}

Submitted on 1 Sep 2010

HAL is a multi-disciplinary open access archive for the deposit and dissemination of scientific research documents, whether they are published or not. The documents may come from teaching and research institutions in France or abroad, or from public or private research centers.
L'archive ouverte pluridisciplinaire HAL, est destinée au dépôt et à la diffusion de documents scientifiques de niveau recherche, publiés ou non, émanant des établissements d'enseignement et de recherche français ou étrangers, des laboratoires publics ou privés. 


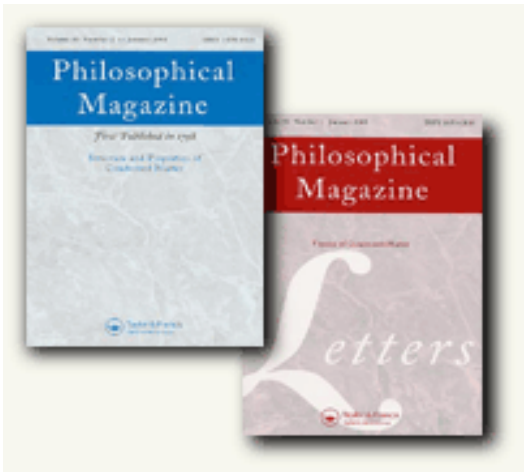

\section{COLD WELDING AND FRETTING TESTS ON QUASICRYSTALS AND RELATED COMPOUNDS}

\begin{tabular}{|r|l|}
\hline Journal: & Philosophical Magazine \& Philosophical Magazine Letters \\
\hline Manuscript ID: & TPHM-05-May-0185.R1 \\
\hline Journal Selection: & Philosophical Magazine \\
\hline Author: & 29-Jun-2005 \\
\hline & $\begin{array}{l}\text { Complete List of Authors: } \\
\text { SALES, Muriel; Austrian Research Center Seibersdorf GmbH, } \\
\text { aerospace material technology } \\
\text { Matériaux et de Métallurgie } \\
\text { Ge Weerd, Marie-Cécile; CNRS Nancy, Laboratoire de Science et } \\
\text { Khare, Varsha; CNRS Nancy, Laboratoire de Science et Génie des } \\
\text { Matériaux et de Métallurgie } \\
\text { Traxler, Gerhard; Austrian Aerospace } \\
\text { Dubois, Jean-Marie; CNRS Nancy, Laboratoire de Science et Génie } \\
\text { des Matériaux et de Métallurgie }\end{array}$ \\
\hline Keywords: & quasicrystals, mechanical properties \\
\hline Keywords (user supplied): & fretting tests, cold-welding, adhesion \\
\hline &
\end{tabular}

\section{S) ScholaroNE \\ Manuscript Central}


4

\section{COLD WELDING AND FRETTING TESTS ON QUASICRYSTALS AND RELATED} COMPOUNDS

M. Sales ${ }^{1}$, A. Merstallinger ${ }^{1}$, P. Brunet ${ }^{2}$, M.C. de Weerd ${ }^{2}$, V. Khare ${ }^{2}$, G.Traxler ${ }^{3}$ and J.M. Dubois $^{2}$ 1: ARC Seibersdorf research, A-2444 Seibersdorf/Austria, muriel.sales@arcs.ac.at, andreas.merstallinger@arcs.ac.at 2: Laboratoire de Science et Génie des Matériaux et de Métallurgie, Ecole des Mines, Parc de Saurupt, F-54042 Nancy 3: Austrian Aerospace, A-1120 Wien

This paper reports a vacuum or space related effect, which is referred to as "cold welding", "adhesion" or "sticking". This effect is studied for bulk quasicrystal [1] versus different kinds of counterparts (steel, aluminium, titanium, hard metals).

Full series of samples, prepared either by crystal-pulling techniques (single crystals) or by sintering (multi-grain samples) were analysed by fretting tests. Four alloy systems were investigated: Al-Pd-Mn, Al-Cr-Fe-B, Al-Cu-B and $\mathrm{Al}-\mathrm{Cu}-\mathrm{Fe}-\mathrm{B}$, with different crystallographic structures and nominal compositions. These materials, especially icosahedral phases, exhibit the absence of cold-welding in vacuum versus certain steels.

Keywords: quasicrystals, cold-welding, fretting tests, adhesion. 


\section{INTRODUCTION ON COLD WELDING}

On spacecrafts, a variety of engineering mechanisms exhibit ball-to-flat surface contacts which are periodically closed for several (thousands of) times. Vibrations occurring during launch or during movement of e.g. antennas in space, can lead to small oscillating movements in the contact, which is referred to as "fretting". This "Fretting" movement can eventually degrade the mechanism surface layers whether they are natural oxides, chemical conversion films or even metallic coatings. This can dramatically increase the tendency of these contacting surfaces to "cold-weld". This lateral motion causes severe destruction and adhesion forces.

In order to gain experience in this effect, a special device - called "fretting facility" - has been developed at the Austrian Research Centre Seibersdorf (ARCS) and was used to investigate several combinations of bulk materials for their tendency towards cold-welding. The test philosophy is based on repeated closing and opening of a pin-to-disc contact. In general, a pin is brought into contact with a disc for several thousand times. For fretting tests, only one static load (ranging from $20 \%$ to $60 \%$ of the elastic limit of the weakest material) is applied for 5000 cycles. During a fretting test, the contact is closed softly (without impact), and while being closed during 10 seconds, fretting is applied to the contact. During the fretting test, a base pressure of 5.10 mbar is sufficient. The adhesion force, i.e. the force required to re-open the contact, is measured at each opening. The uncertainty of measurement was done by statistical analysis of experimentally derived data based on GUM type A: the uncertainty is $+/-20 \%$ (single sigma).

This kind of adhesion is not visible in air, because in air only fretting corrosion is visible: the oxide layer is always present at the top of the material and protects it against cold-welding. All these fretting tests are done in vacuum, because on one hand no adhesion is detected for a fretting test in air (whatever the substrate), and on the other hand, these quasicrystals aimed to be used later on in space (coating made of quasicrystals were elaborated afterwards for space applications). "No adhesion" means noise. The indication of low and high adhesion is related to comparison of adhesion force values themselves (data from general materials [2]). A fretting is "successful", if there's no adhesion during 5000 cycles at least.

To check if an adhesion value is true or just noise, "buffer files" are exploited: a buffer file represents the end of each cycle, when the pin is separating from the disc. It's the force during the unloading in function of the time. In this case of true adhesion, a negative force between the pin and the disc is seen, which refers to tension between pin and disc. The breaking force is referred to as "adhesion force" (It is the jump of the force). If the jump is high, the adhesion is high. If the jump is not very high, the adhesion is low. And if there's no jump of the force, there's no adhesion, only noise.

During the fretting test, there's a micro-plastic deformation. After each cycle the shape of the contact area is different, because of this micro-plastic deformation. We have a wear of the materials (wear of disc and/or of pin). There's a time-dependant changes of adhesion forces. For each cycle we have one value of the adhesion force. From all these "adhesion force" values only the maximum is taken (for bulk materials, no coatings). This approach reflects engineering objectives, i.e. to provide values for design of mechanisms [2]. Details can be found in reference [3].

\section{RESULTS ON FRETTING}

Different three bulk icosahedral phases and five approximants presented in figure 1-a were analysed versus different counterparts.

Single crystals (an icosahedral phase and its approximant) were tested under fretting tests on vacuum. The figure 1-b shows that the adhesion force of quasicrystals versus metallic alloys (even for the approximant) is lower than alloys versus themselves. The icosahedral phase $i-A l_{70} P d_{22.1} M n_{7.9}$ shows no adhesion versus the bearing steel AISI 52100 and the stainless steel SS 316L.

Two icosahedral phases and four approximants were analysed.

For approximants, the figure 2-a shows that adhesion is detected for all these tests, except for $\mathrm{Al}_{50} \mathrm{Cu}_{40} \mathrm{Fe}_{10}$ versus steel AISI52100 and $\mathrm{Al}_{41.8} \mathrm{Cu}_{57.2} \mathrm{~B}_{1}$ versus WC. As reference and for comparison, very high adhesion for steel A286 versus itself was found because of the high Ni content. 
Three different icosahedral phases were also analysed: two sintered quasicrystals i- $A l_{62.5} \mathrm{Cu}_{25.3} F e_{12.2}$ and i$A l_{59.5} \mathrm{Cu}_{25.3} \mathrm{Fe}_{12.2} \mathrm{~B}_{3}$ and one single crystal $i-A l_{70} P d_{22.1} \mathrm{Mn}_{7.9}$.

For these three icoshaedral phases, the figure 2-b shows that no adhesion versus steels AISI 52100, A286 and SS 316L was detected (except for $\mathrm{i}-\mathrm{Al}_{59.5} \mathrm{Cu}_{25.3} \mathrm{Fe}_{12.2} \mathrm{~B}_{3}$ versus $\mathrm{SS} 316 \mathrm{~L}$, a very low adhesion is noticed). But with Ti6Al4V and Al7075 counterparts, high adhesion was found.

It is remarkable that the adhesion between stainless steels and icosahedral crystals is much lower than for stainless steels in contact to themselves. Similar conclusion is valid for the aluminium alloy (Al7075 versus itself: $7330 \mathrm{mN}$ ). Therefore, the adhesion forces between quasicrystals and steels or titanium (even Al7075) were found to be negligible in comparison to typical metals for space applications.

\section{RESULTS ON WEAR VOLUMES}

To complete fretting test knowledge, wear volumes of both pin and disc are measured with an optical profiler with a 3D topography. This system enables to calculate volumes, i.e. a volume below or above the "zero plane". After a fretting test, the wear mark is often a hole (sometimes a hole with a deposition of pin material too, see figure 3-a). Then the worn volume refers to a hole or a hole with a deposition. Nevertheless, the volume is easily calculated by the system (see figure 3-b). Afterwards, wear data is related to adhesion.

The wear volume (material volume which is lost or added) from or onto the contact area was also calculated.

The general tendency of the figure 3-b is that the absence of adhesion is related to a low wear volume. Conversely, high adhesion reveals high wear volume (with debris too). As a result, all approximant systems are much more brittle than icosahedral quasicrystals. Moreover, especially for samples with high adhesion, a big amount of loose debris was formed, which would be detrimental for space applications. Under non-gravity, these debris particles would fly around and would contaminate the whole spacecraft.

In fretting tests, icosahedral phases show no adhesion versus bearing steel AISI52100 (Fe, $\mathrm{Cr}$ ) and even not for stainless steel A286 (Fe, Cr, Ti, Ni). The latter is of austenitic phase and therefore prone to strong adhesion, if it would be in contact to itself. However, low adhesion is noticed versus stainless steel SS316, and high adhesion is found versus aluminium $\mathrm{Al} 7075$ and titanium alloy (Ti6Al4V). Thus, for $\mathrm{i}-\mathrm{Al}_{62.5} \mathrm{Cu}_{25} \mathrm{Fe}_{12.5}$ and $\mathrm{i}$ $\mathrm{Al}_{59,5} \mathrm{Cu}_{25,3} \mathrm{Fe}_{12,2} \mathrm{~B}_{3}$, no adhesion versus steels AISI52100 and A286 is noticed, combined with a low wear volume. For the approximant $\mathrm{Al}_{50} \mathrm{Cu}_{40} \mathrm{Fe}_{10}$, there is no adhesion versus steel AISI52100 and low adhesion versus space steel A286, with low wear volumes too.

\section{SEM PICTURES AND EDX ANALYSIS}

To complete our fretting test knowledge, pin and discs were analysed with a SEM (Scanning Electron Microscope). In conjunction with SEM pictures, an Energy Dispersive X-ray Analysis (EDX) was used to determine the elemental composition of the surfaces (holes, deposits or original surfaces without wear). From SEM and EDX analysis, either metallurgical processes (during annealing) or wear mechanisms during the fretting test are deduced.

After this fretting test, there is a hole on the disc and a deposition of material on the pin, made of $\mathrm{Al}, \mathrm{Cu}$ and $\mathrm{Fe}$ (see figure 4): the worn and lost disc material is sticking on the pin. Surface is strongly changed due to fretting. For comparison, a fretting test of a A286 steel disc versus itself shows strong surface destruction due to adhesive wear (the contact area of the disc after the fretting test is a hole with a depth of $-55 \mu \mathrm{m}$ and a diameter of 0.675 $\mathrm{mm}$ ), combined with high adhesion force (maximum of adhesion $16718 \mathrm{mN}$ ). Material is worn out of the surface and pressed back or adheres to the contact partner.

The duration of all these fretting tests is similar ( 5000 cycles). Not only there is no adhesion between quasicrystals and steels AISI52100 and A286, but also the wear of a quasicrystal disc versus steel is much lower than steel versus itself (see table 6 for wear volumes). 


\section{CONCLUSION}

Several single crystals and bulk sintered quasicrystals and approximants were tested against fretting. Quasicrystalline compounds, especially the icosahedral $\mathrm{Al}-\mathrm{Cu}-\mathrm{Fe}-(\mathrm{B})$ system have the best performance in terms of fretting tests.

The two bulk sintered icosahedral phases i- $\mathrm{Al}_{62.5} \mathrm{Cu}_{25} \mathrm{Fe}_{12.5}$ and i- $\mathrm{Al}_{59,5} \mathrm{Cu}_{25,3} \mathrm{Fe}_{12,2} \mathrm{~B}_{3}$ present a potential for antifretting applications in vacuum against a steel counterpart, because they avoid adhesion versus steels AISI52100 and A286, combined with a low wear volume (thus no emission of debris). Furthermore, low adhesion is detected versus the stainless steel SS316L, combined with a low wear volume too (again with no debris). But both icosahedral phases cannot prevent cold-welding against titanium Ti6Al4V and aluminium Al7075 alloys, because high adhesion is noticed, (combined with a high wear volume for Ti6Al4V and formation of debris).

\section{ACKNOWLEDGEMENTS}

The European Community is acknowledged for supporting this study through the project SMART QUASICRYSTALS, under the "Competitive and Sustainable Growth" programme (Contract $\mathrm{N}^{\circ}$ G5RD-CT2001-00584). We are grateful to FZ Jülich (Germany) for the preparation of single-crystals.

\section{REFERENCES}

[1]: Dubois J.M.; "Useful Quasicrystals" (World Scientific, Singapore, 2005).

[2] A. Merstallinger, E. Semerad, B.D. Dunn, "influence of coatings and alloying on cold welding due to impact and fretting", Proc. 9h European Space Symposium on material in a Space environment, ESTEC Noordwijk (NL), June 2003.

[3]: Merstallinger A., Semerad E; “Test Method to Evaluate Cold Welding under Static and Impact Loading”, Inhouse-Standard by Austrian Research Centre Seibersdorf, Issue 1 (1995), Issue 2 (1998). 


\section{FIGURE CAPTIONS}

Fig 1: (a) Composition and mechanical data of quasicristals and counterparts used for these fretting tests. (b) Comparison of adhesion force under fretting for single crystals. Adhesion between metals under fretting is higher than for quasicrystals. No adhesion between i- $\mathrm{Al}_{70} \mathrm{Pd}_{22.1} \mathrm{Mn}_{7.9}$ and steels AISI 52100 and A286. For other tests, low or high adhesion is detected.

Fig 2: (a) Comparison of adhesion force under fretting for approximants. Adhesion between metals under fretting is higher than for approximants. No adhesion between $\mathrm{Al}_{50} \mathrm{Cu}_{40} \mathrm{Fe}_{10}$ and steel AISI52100 and $\mathrm{Al}_{41.8} \mathrm{Cu}_{57.2} \mathrm{~B}_{1}$ and WC. For other tests, low or high adhesion is detected. (b) Comparison of adhesion force under fretting for icosahedral phases.

Fig 3: (a) Contact area of the disc after the fretting test $\mathrm{i}-\mathrm{Al}_{62.5} \mathrm{Cu}_{25.3} \mathrm{Fe}_{12.2}$ versus A286: there is a hole with a depth of $-8.3 \mu \mathrm{m}$ and a diameter of $0.304 \mathrm{~mm}$. (b) Wear Volumes $\left(10^{-5} \mathrm{~mm}^{3}\right)$ of discs. Legend: adhesion, low adhesion, no adhesion (noise). Grey graduation colours refer to the graphs (figures 1(b), 2(a) and 2(b)) indicating the level of adhesion, to see the relation between the wear volume (volume of disc which is lost), and results of fretting test.

Fig 4: SEM picture (back-scattered electron imaging) and EDX analysis of the contact area of the disc after the fretting test $\mathrm{i}-\mathrm{Al}_{62.5} \mathrm{Cu}_{25.3} \mathrm{Fe}_{12.2}$ versus $\mathrm{A} 286$ (No adhesion): only $\mathrm{Al}, \mathrm{Cu}$ and $\mathrm{Fe}$ from the quasicrystal is present (no pin material). 
(a)

\begin{tabular}{|c|c|c|c|c|c|}
\hline Designations & compositions & HV & Y & Poisson & E \\
\hline short & W\% & daN/mm & MPa & & GPa \\
\hline AlCrFeBMo & Al74.5Cri5Fe6B3M01.5 & 516 & 1985 & 0.3 & 140 \\
\hline ksi'-AlPdMn & $\xi^{\prime}$-Al73.9 Pd22.2 Mn3.9 & 1000 & 3846 & 0.4 & 100 \\
\hline i-AlPdMn & i-Al70Pd22.1Mn7.9 & 1000 & 3846 & 0.4 & 100 \\
\hline i-AlCuFeB & i-Al59.5Cu25.3Fe12.2B3 & 578 & 2223 & 0.3 & 140 \\
\hline AlCuB & Al41.8Cu57.2B1 & 710 & 2731 & 0.3 & 140 \\
\hline i-AlCuFe & i-Al62.5Cu25.3Fe12.2 & 530 & 2038 & 0.3 & 140 \\
\hline gamma-AlCrFe & y-Al67.6Cr23.3Fe9.2 & 842 & 3238 & 0.3 & 140 \\
\hline beta-AlCuFe & B2-Al50Cu40Fe10LZ & 541 & 2081 & 0.3 & 140 \\
\hline AlSI316L & FeMnCrSiMoNi & 175 & 675 & 0.28 & 190 \\
\hline Al7075 & AlMnZn & 170 & 654 & 0.33 & 72 \\
\hline A286 & FeCrNiTi & 297 & 1142 & 0.28 & 200 \\
\hline Ti-IMI 318 & Ti6Al4V & 318 & 1223 & 0.32 & 114 \\
\hline AlSI52100 & FeCr & 700 & 2692 & 0.28 & 200 \\
\hline
\end{tabular}

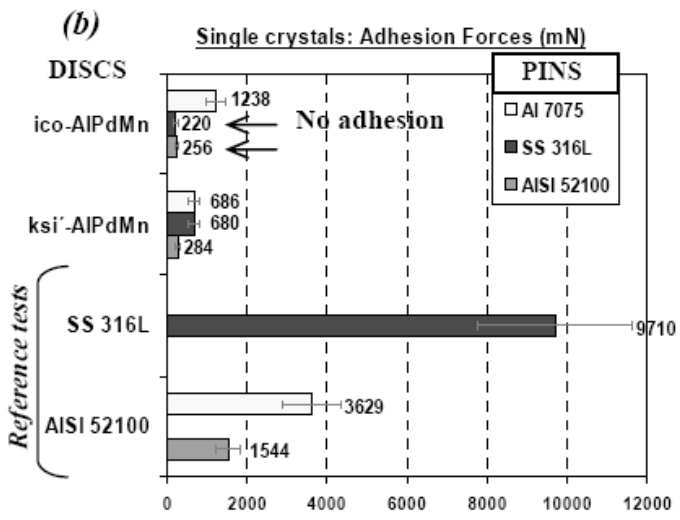

Figure 1
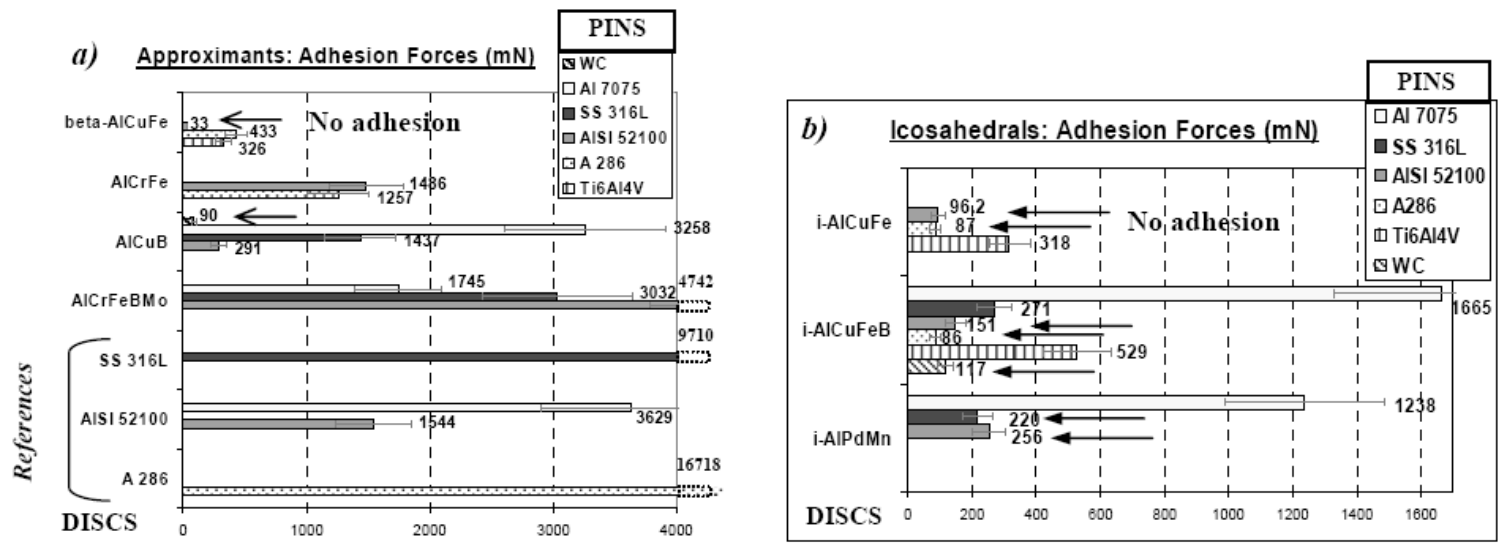

Figure 2

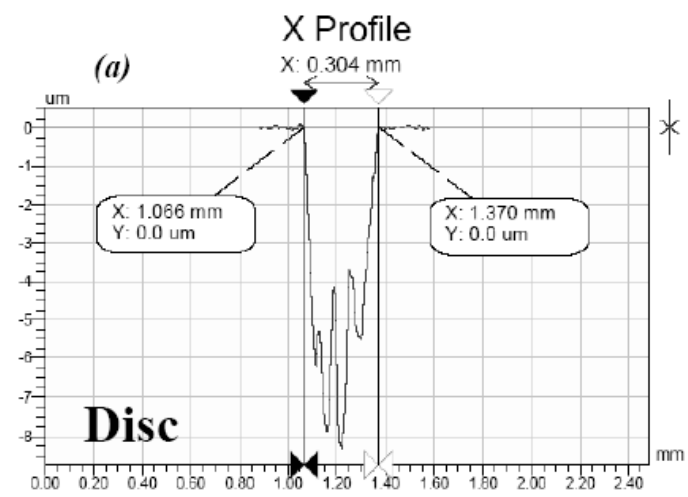

$\leftarrow \mathrm{X}$ profile of the contact area of the disc after the test.

$\downarrow$ Wear volumes of worn discs after the fretting test.

(b)

\begin{tabular}{|c|c|c|c|c|c|c|}
\cline { 2 - 7 } \multicolumn{1}{c|}{} & \multicolumn{6}{c|}{ WEAR VOLUMES $(10-5 \mathrm{~mm} 3+/ 20 \%$ ) } \\
\hline Discs / Pins & AISI 52100 & AISI316L & Al7075 & WC & Ti6Al4V & A286 \\
\hline AICrFeBMo & $>55000$ & $>55000$ & 51106 & $/$ & $/$ & $/$ \\
\hline ksi'-AlPdMn & 2369 & 22523 & 16 & $/$ & $/$ & $/$ \\
\hline AlCuB & 18 & 9 & 4 & 8 & $/$ & $/$ \\
\hline AlCrFe & $>55000$ & $/$ & $/$ & $/$ & $/$ & $>55000$ \\
\hline beta-AICuFe & 8 & $/$ & $/$ & $/$ & 60 & 32 \\
\hline i-AlPdMn & 2042 & 140 & 73 & $/$ & $/$ & $/$ \\
\hline i-AlCuFeB & 13 & 39 & 3 & 29 & 75367 & 11 \\
\hline i-AlCuFe & 15 & $/$ & $/$ & $/$ & 11123 & 37 \\
\hline
\end{tabular}

Figure 3 

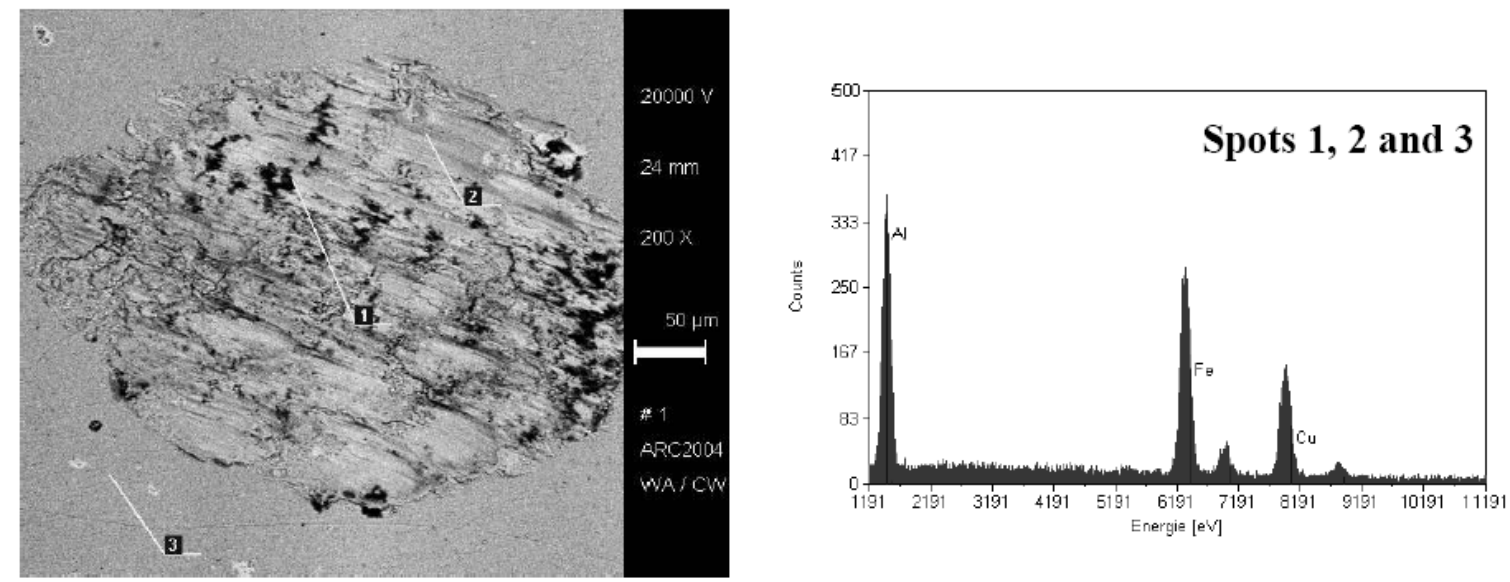

Figure 4 